AGH DRILLING, OIL, GAS • Vol. $31 \cdot$ No. $1 \cdot 2014$

http://dx.doi.org/10.7494/drill.2014.31.1.117

B.V. Kopey*, S. Bednarz ${ }^{* *}$, O.I. Stefanyshyn***

\title{
PREDICTION OF PUMPING UNITS REDUCERS' RESOURCE
}

Designing of any complex technical system - the first and main stage, during which the designer projects the certain level of reliability. Therefore, at different stages of the equipment design it is necessary to predict the expected reliability. The prediction is particularly important in the early stages of design, when you need to compare different options for the reliability block diagrams designed system and its units, which makes it possible to take timely measures to improve the reliability.

The basic principle of equipment reliability forecasting in the design process should be a systematic approach that takes into account the specifics of design, manufacturing capabilities and operating conditions. The reliability of modern machines and equipment for oil industry in predicting are considered as complex systems consisting of a large number of parts and assembly units that are functionally related to each other [1].

Costs for maintenance and repair are some of the important performance indicators of any technical system. The reducing of costs in cases when the equipment has high level of maintainability, practically is impossible without effective control of the equipment. Vibration diagnosis is often used for quality control of manufacturing on output (or repair ) for defecting before repair or to identify defects and observation of their development during the operation.

To conduct the vibration diagnostics in service of gear reducers is an important method of preventing the accidents. Vibration diagnostics in service of reducers is conducted to identify the changes and the prediction of vibration is made to know technical state, including each of its elements for which there is a real probability of failure between repairs.

Periodic monitoring of pumping units reducer vibration allows a prediction of its full or residual resource to the next repair, which can be estimated on the basis of extrapolation

\footnotetext{
* Ivano-Frankivsk National Technical University of Oil and Gas, Ukraine

** AGH, University of Science and Technology, Faculty of Drilling, Oil and Gas, Krakow, Poland

*** Borislav Central Base of Production Servicing, Ukraine
} 
methods and classification [2]. Considering these two methods, we can say that the advantage of extrapolation method has its high accuracy and the possibility of adaptation to each specific gear, and the disadvantages include its complexity and the need to respect the conditions of constant change over time the vibration characteristics of the selected gear by law of distribution. In the application of classification method, which is simple, you need to process a certain amount of statistical data derived from the operation of sucker rod pumping unit or perform experiments on a special stand that is relatively complex. In addition, the practice shows that the use of statistical techniques often don't makes accurate predictions due to the large gap of pumping units working regimes and various properties of the pumped wells products, so the decision was made in solving this problem by use the method of construction and extrapolation of time trend change of gear reducer operating parameters.

Analysis of the literature on this subject in order to find examples of residual life forecasting of equipment of oil and gas industry did not give significant results. Most publications reveal purely theoretical approaches to this problem and they describe only the general case, which was taken as a basis for solving the problem of prediction of a technical condition of reducer gearboxes.

Detection of defects at the stage of their initiation makes it possible to observe their development and timely plan for carrying out the repair and maintenance of gear reducer. This process can be carried out for several years, when the variety of defects both in volume and quality, will not lead to an emergency. Of course, this approach is possible only when all potentially dangerous defects are detected at an early stage of development. To detect defects at an early stage of development the diagnostic features are used, which are determined by the spectral analysis of vibration or power oscillation. The main feature of defects in gear reducer bearings is changing the properties of the friction force and high-frequency vibration, resulting from this. These changes appear as micro shocks or periodic changes in the coefficient of friction at the contact surfaces of friction defective, easily detectable by spectral analysis of vibration bearing unit housing $[3,4]$.

The very important task during the life of the gear reducer of pumping unit is to predict the moments of parts replacement to prevent the failure of components of the gear and equipment in general.

The main problem in diagnosing of tooth meshing defects (renovated after repair) in the gearbox of pumping unit is the lack of standardized information according allowable vibration. Therefore, the great importance in diagnostics of gear pairs is the comparison of the current range of the vibration with the spectrum of vibration, registered in the previous measurement, which was performed at the proper gear reducer.

The complexity of the normalization of tooth meshing vibration is that in the gearbox is not fully logged off vibration that occurs during tooth meshing, but only part of it, which could be transmitted on the complex ways in gear to the sensor. The options in this way in a variety of different types of gear are divers.

Depending on the route of transmission of vibration signals from the sensor to the tooth meshing area is its damping, so it is important to place the installation of sensors in the diagnosis of gearbox. 
We investigated a number of gears that operated in Boryslav CBPS and operating conditions that are approximately the same. Maintenance of gear were held on the Boryslav CBPS, and therefore the technology of manufacturing and assembly of equipment after repair has been the same. From the above mentioned it can be concluded that the only information on the technical condition and the following prediction can be obtained using diagnostic vibration information.

In the conditions of Borislav CBPS we conducted diagnostic examination of a number of gearboxes PH-2300 and determined the optimal level of vibration, whereby it can be concluded the qualitative repair of this type of gear.

The sensors during testing were installed on the gear housing near the output shaft. The average frequency of rotation of the input shaft gear during vibration control was respectively: $f_{\text {in }}=3.9 \mathrm{~Hz}$ and $f_{\text {in }}$ ' $=3.53 \mathrm{~Hz}$. The processing of the results was conducted by software MathCad.

The spectral characteristics of the vibration signal of gear after the repair are shown in Fig. 1. For repaired gear the maximum is not clearly defined and has small amplitude. We conclude the optimal average value of vibration, which is $1.7 \mathrm{~mm} / \mathrm{s}$.

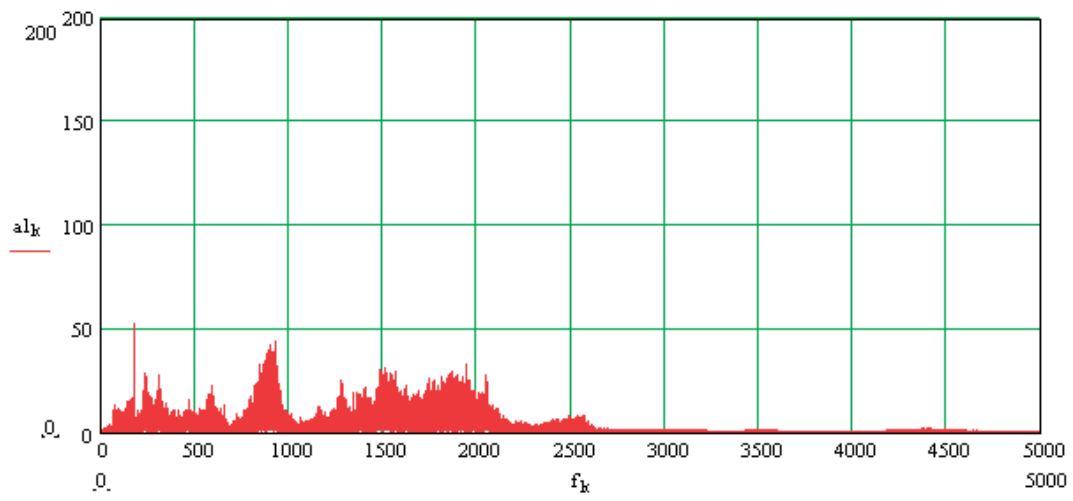

Fig. 1. The spectrum of reducer vibration after the repair

For the worn gear the side bands remote from tooth meshing frequency have been observed to the frequency of rotation of the output shaft of the gearbox, and less observed -to the rotational speed of the intermediate shaft. The presence of such side harmonics indicate a defect of gear that rotates with the corresponding frequency (in this case, of output and intermediate shaft). One of vibration spectra is shown in Figure 2. The average vibration velocity is $2.9 \mathrm{~mm} / \mathrm{s}$.

Acceptable level of vibration that is recommended by standard GOST ISO 8579-2-2002 for gear PH -2300 is $8.3 \mathrm{~mm} / \mathrm{s}$, which can be used to determine its suitability for further exploitation [5]. According to calculations conducted by an appropriate method the acceptable level of vibration of above mentioned gear is $3.1 \mathrm{~mm} / \mathrm{s}$. These valid values are in good agreement with the experimental values and have a lower level compared to the standard recommendations. 


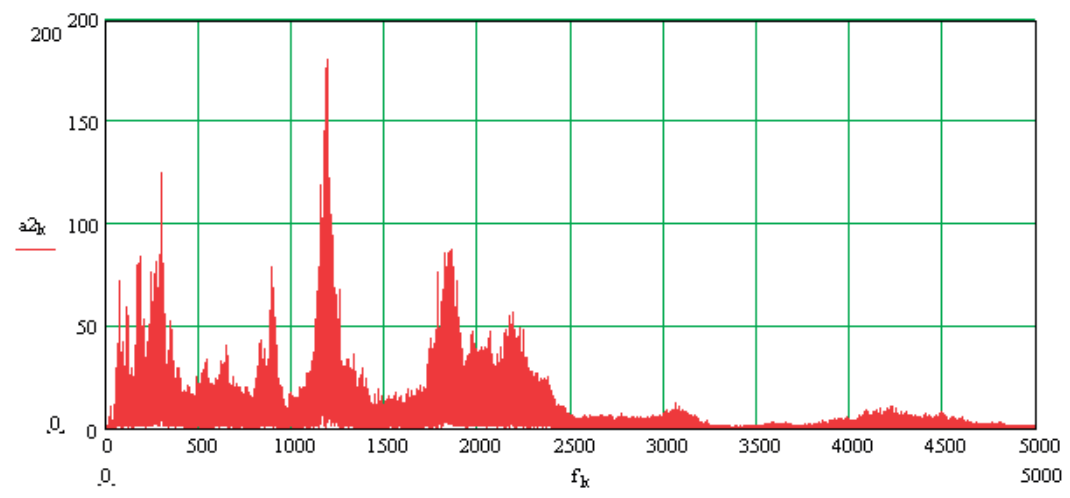

Fig . 2. Vibration spectrum of worn gear

According to conducted research the curve of life prediction of gear reducer has been built (Fig. 3). Thus, the expected service life of the gear RN -2300 will be $36-38$ thousand of hours.

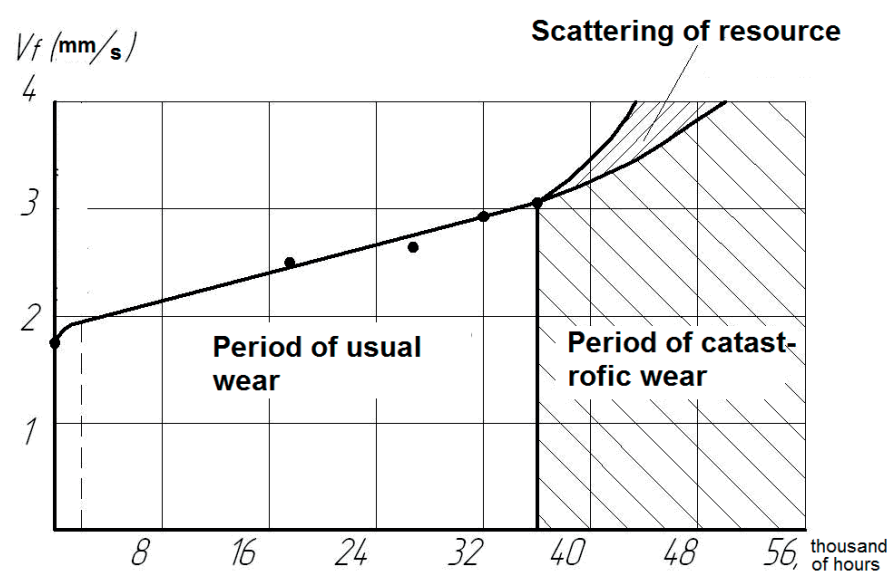

Fig. 3. Curve of gears predicting longevity

Prediction of residual life refers to a specific type of gear. The basis for the prediction is information that can be divided into three parts. Firstly, there is information about the search of defects in service. To do this continuously we receive the diagnostic information. Secondly, this information is about the loads and other conditions of the gear interaction with the environment.

Diagnostic information is limited by volume and is relative. Diagnosis does not allow the identifying of all damage and cracks which in the future could result in marginal conditions. There is a high probability of non detection of defects due to imperfect equipment, negligence of the operator and when the location of the defect is not available. Data on the 
mode of loading is also an important source of information. Thus, the two sources of information - diagnostic information about the technical condition of the gear and data loads are closely related and mutually independent. One of the important types of information on the prediction stage is the volume of data on materials, elements, components, technology, manufacturing and assembly of the gear during the repair, i.e. information that is the basis of resource forecasting in the design stage.

In order to reduce the effect of vibration amplitude on the vibration characteristics of the gearbox we used Hado-technology with the addition of soft metals to lubricants. Studies were conducted on a model plant of reducer. In the gearbox model sump oil I- 40 has been poured with the addition of Hado for mechanical transmissions and gearboxes, produced by " Hado-technology ." After period of preworking (according to manufacturer's instructions) in the gearbox sump we added 7.5\% of fine copper powder PG- 19M -01 TU 322-19-004-96. In the operation were observed the frequency spectra of vibration of reducer model (Fig. 4 ).

These spectra are almost the same for the average level of vibration, but with some local differences, distinguishable by their superposition (Fig. 4c).

a)

A

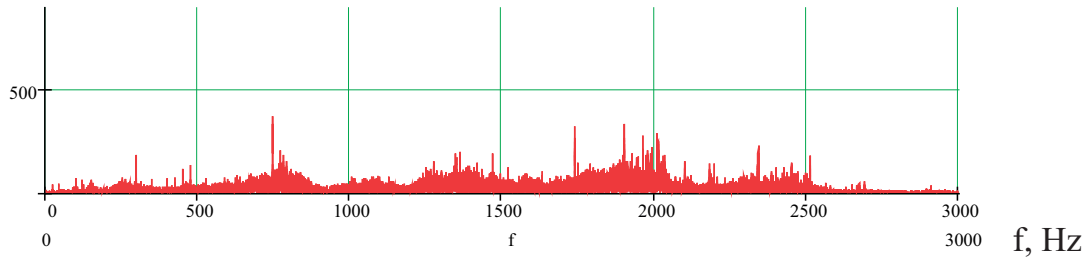

A

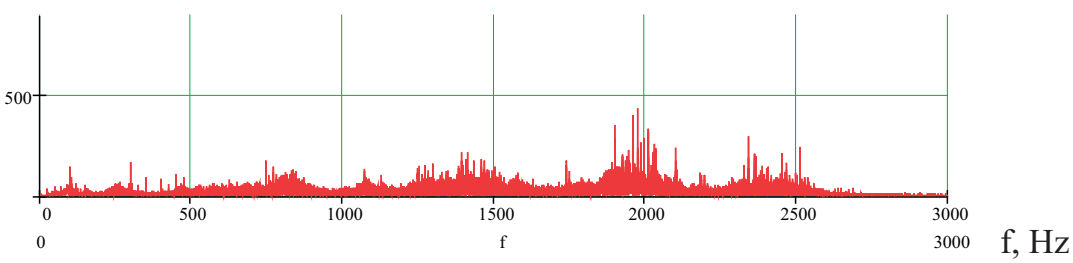

b)

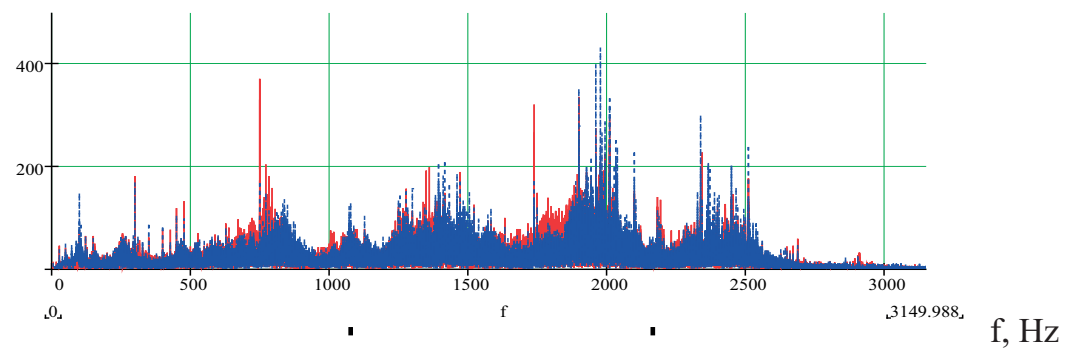

c)

Fig. 4. Spectra vibration of gear reducer

a) the use of oil I- 40 with the addition of Hado , b ) the use of oil I- 40 with the addition of Hado and copper powder to the lubricant ;c) the combined spectra 


\section{REFERENCES}

[1] B.Kopey, O. Stefanyshyn, I.Kopey.Reliabity analysis of reducing gears of pumping jacks. Prospecring and development of oil and gas deposits, № 4(21), 2006, c.96-99 (in ukrainian).

[2] Rusov I.A. Spectrum vibrodiagnostics.- 1996 // www.vibrocenter.ru/book.htm

[3] J.F.Lea, J.F.Bowen. Dynamic measurement of beam-pump parameters // SPE production engineering, 1992. - P.113-120

[4] www.reductor-news.ru

[5] Вибрация. Контроль вибрационного состояния зубчатых механизмов при приемке: ГОСТ ИСО 8579-2-2002 [Чинний від 01.11.2007].-М.: Стандартинформ, 2007.-10c. 